\title{
The Samuel F. B. Morse statue in Central Park: scientific study and laser cleaning of a 19th-century American outdoor bronze monument
}

\author{
Elena Basso ${ }^{1^{*}}$, Federica Pozzi ${ }^{1}$ and Matthew C. Reiley ${ }^{2}$
}

\begin{abstract}
Many of Central Park's bronze statues were coated with lacquer as a protective measure between the late 1970s and early 1990s. In several cases, these coatings outlasted their performance life and were no longer adequately protecting the sculptures. In 2010, a cyclical campaign to remove and refurbish the coatings provided an opportunity to closely assess the condition of de-coated surfaces and to develop suitable, sustainable treatment approaches. The Samuel F. B. Morse statue, created in 1870 by Byron Pickett, commemorates the 19th-century painter and inventor known for the telegraphic code that bears his name. Initially, samples from this statue were collected on the field and analyzed with various techniques to characterize the degradation products that were heavily affecting its surface and the organic coatings used to protect the bronze. Various corrosion species, mainly sulfates and chlorides, were identified by X-ray powder diffraction (XRD), while pyrolysis-gas chromatography/mass spectrometry (Py-GC/MS) revealed that the organic coatings were based on mineral wax and acrylics. These results informed a decision to relocate the statue to a controlled workshop space to aid in the manipulation of the large figure and optimize cleaning by laser ablation. Treatment was monitored through three campaigns of analysis using portable X-ray fluorescence (pXRF) spectroscopy, performed on select locations, to characterize the extent of corrosion across the sculpture's surface and monitor changes on the target areas throughout the cleaning. Following the initial phase of treatment, pXRF showed the substantial removal of iron- and lead-rich compounds from the brownish-toned coating and atmospheric pollution deposition. In the subsequent treatment phases, variations in the relative amounts of sulfates and chlorides were noted and further investigated through the examination of a cross section by means of scanning electron microscopy coupled with energy-dispersive X-ray spectroscopy (SEM/EDS). Based on the findings of iron-containing pigments in the organic coating, a decision to apply a new, similar, translucent, brown-toned coating containing such coloring materials was made to achieve the desired visual nuance for the finish and provide additional corrosion protection to the bronze. Scientific analysis on the Morse statue has helped characterize its materials, methods of fabrication, and current conditions on a microscopic scale; in addition, it has guided the means and methodologies of treatment and relays essential information useful for future preservation.
\end{abstract}

Keywords: Outdoor sculpture, Laser cleaning, Conservation, 19th century, Coating, Gunmetal, Corrosion

*Correspondence: elena.basso@metmuseum.org

${ }^{1}$ Department of Scientific Research, The Metropolitan Museum of Art, 1000 Fifth Avenue, New York, NY 10028, USA

Full list of author information is available at the end of the article

\section{Introduction}

More than fifty bronze sculptures have been placed in Central Park since its founding in the mid-19th century. Bronze, meant as representative of a wide range of copper alloys, is the most widespread material used in sculpture
Springer Open

(c) The Author(s) 2020. This article is licensed under a Creative Commons Attribution 4.0 International License, which permits use, sharing, adaptation, distribution and reproduction in any medium or format, as long as you give appropriate credit to the original author(s) and the source, provide a link to the Creative Commons licence, and indicate if changes were made. The images or other third party material in this article are included in the article's Creative Commons licence, unless indicated otherwise in a credit line to the material. If material is not included in the article's Creative Commons licence and your intended use is not permitted by statutory regulation or exceeds the permitted use, you will need to obtain permission directly from the copyright holder. To view a copy of this licence, visit http://creativeco mmons.org/licenses/by/4.0/. The Creative Commons Public Domain Dedication waiver (http://creativecommons.org/publicdomain/ zero/1.0/) applies to the data made available in this article, unless otherwise stated in a credit line to the data. 
in the United States [1]. It is more resistant than some types of stone (e.g. carbonate stones, sandstone) to outdoor environmental conditions, nonetheless bronze corrosion represents a severe issue that requires constant monitoring of an object's conservation state and related interventions. Exposed to a variety of atmospheric agents over the years, the condition of the park's sculptures was dramatically compromised after the industrial revolution and the resulting increase of pollution. This situation was further undermined by the fact that New York City is located in a coastal environment, where marine chlorides in the local atmosphere may significantly contribute to the physicochemical degradation of bronzes. Starting from the 1970s, further concerns were raised about acid rain effects on outdoor cultural heritage. In the case of outdoor bronzes, in particular, acid attack appears to be more effective on corrosion patinas rather than on the bare metal [2].

Beginning in the late 1970s, many of Central Park's bronze statues were coated with lacquer as a protective measure. In several cases, these coatings outlasted their performance life and were no longer adequately protecting the sculptures. In 2010, a cyclical campaign to remove and refurbish the coatings provided an opportunity to assess the condition of de-coated surfaces, to develop suitable treatment approaches, and to consider context and sustainability of such treatments through a contemporary lens. Originally installed on the Central Park Mall, the Samuel F. B. Morse memorial was moved to its current location near Fifth Avenue at East 72nd street in 1988. When it was dedicated in 1871 , the stately bronze figure of the 19th-century painter and inventor became the last monument in Central Park to honor a living person. Morse (1791-1872), a founder and the first president of the National Academy, is portrayed with his left hand resting on a single line telegraph machine (Fig. 1). Created by sculptor Byron M. Pickett (1833-1907) and cast by M. J. Power Bronze Founder of New York, the statue was well received, and a bust version was reproduced and offered for sale to the public.

Over time, the statue's surface has suffered from severe degradation. Exposed areas are deeply pitted, and sculptural detail has been lost as a consequence of decades of unprotected exposure to corrosive atmospheric agents such as salts and acid rain. Furthermore, blisters of active corrosion and associated localized coating failure have long been noted in the deep recesses of the figure's long coat. These observations prompted conservation staff at the Central Park Conservancy (CPC) to undertake a research project aimed to investigate the ongoing issues and formulate an adequate treatment. The Morse statue was thus removed from its granite base and relocated to a controlled workshop space to aid in the manipulation

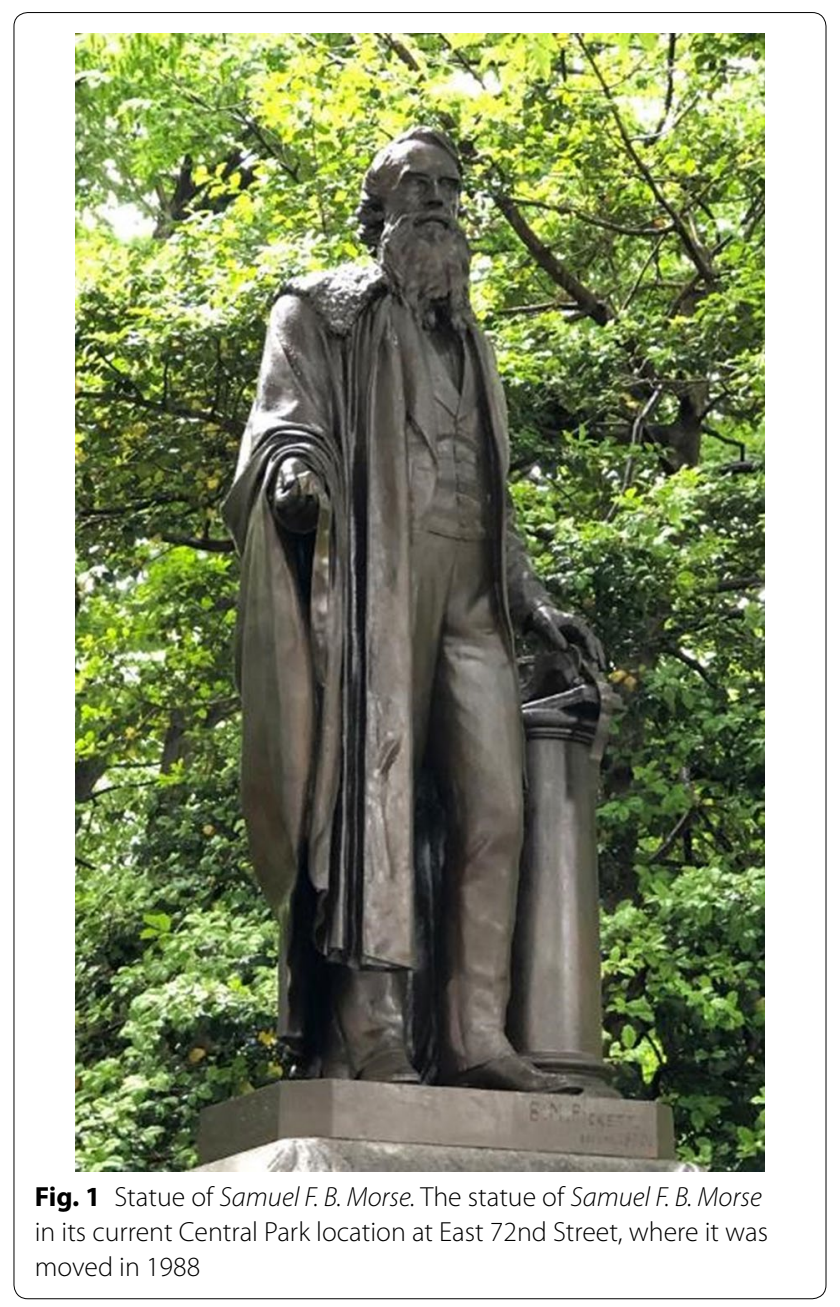

of the large figure and in devising a cleaning and recoating plan. The need of a precise, quick, and safe approach for the object, conservators, and the environment guided the choice of treatment towards laser cleaning. This treatment uses specific, tunable laser parameters such as wavelength, as well as pulse frequency and duration, to preferentially excite and safely remove undesired coatings or contaminants from a surface through photomechanical, photothermal, and photochemical reactions [3]. Among its successful applications, laser cleaning has proven highly effective for removing corrosion products from bronze sculptures [3-9] and archaeological objects [10-13]. One of the main advantages of this cleaning methodology is the possibility to select suitable settings for achieving the expected results, preventing the operator from damaging the artwork [14].

In the present work, various techniques of scientific analysis were used to shed light on the conservation state of the Samuel F. B. Morse statue and to offer guidance to conservators during the cleaning treatment. In detail, 
$\mathrm{X}$-ray powder diffraction (XRD) revealed the exact nature of the corrosion products found on the sculpture's surface, mostly consisting of sulfates and chlorides, while optical microscopy and scanning electron microscopy with energy-dispersive X-ray spectroscopy (SEM/EDS) provided precious information on their distribution and thickness within a cross section's stratigraphy. In addition, pyrolysis-gas chromatography/mass spectrometry (Py-GC/MS) was employed for the characterization of the organic coatings covering the statue, revealing a combination of mineral wax and acrylics. Notably, three analytical campaigns using portable X-ray fluorescence (pXRF) spectroscopy were also carried out to monitor the substantial removal of the Morse figure's unstable bronze condition and its failing lacquer coating. The Conservancy's goal for conserved bronzes in the Central Park's collection-with input and oversight of New York City's Design Commission-is to impart minimal net change from the sculpture's intended appearance. Therefore, with these considerations in mind and based on the detection of iron-containing pigments in the sculpture's organic coatings, a decision was made, following the laser cleaning treatment, to apply a new, similar, translucent, brown coating containing such coloring materials to achieve the desired visual nuance for the finish and provide additional corrosion protection to the bronze.

Scientific analysis on Central Park's Samuel F. B. Morse statue has provided significant insight into the materials, methods of fabrication, previous treatments, and current condition issues of this outdoor sculpture on a microscopic scale; in addition, it has offered invaluable guidance in the choice of the means and methodologies of treatment and relays essential information useful for future preservation.

\section{Experimental}

A careful visual assessment of the conservation state of the Morse sculpture provided initial information on the distribution of the translucent, brown organic coating on the statue's surface and locations where such coating was missing, as well as on the presence of green and red corrosion products. To investigate the ongoing condition issues, thirteen microscopic samples were removed from corroded areas using a metal scalpel (Table 1). Most of these samples were analyzed by XRD in the form of scrapings, whereas one was embedded in EpoThin ${ }^{\mathrm{TM}} 2$ epoxy resin and mounted as a cross section, abraded using Micromesh ${ }^{\circledR}$ cloths and then finely polished with diamond pastes $(6,3,1,0.25$ micron) on wool cloths in preparation for SEM/EDS analysis. One sample of organic coatings was also removed from the surface in an adequate amount for Py-GC/MS analysis. Portable XRF was then used non-invasively to monitor the laser cleaning treatment through point analysis of several select areas on critical locations of the sculpture.

$X R D$ Analysis was performed using an open-architecture Philips PW1835 X-ray diffractometer and PW1710 controller on thirteen samples, selected on the basis of macroscopic observations, primarily in correspondence of uncoated areas affected with pustules of active corrosion. Samples were finely ground in an agate mortar and mounded with acetone on low-background silicon $(\mathrm{Si})$ (510) plate. Diffraction patterns were collected between $5^{\circ}$ and $70^{\circ} 2 \theta$, using copper $(\mathrm{Cu}) \mathrm{K} \alpha$ radiation, set at $40 \mathrm{kV}$ voltage and $30 \mathrm{~mA}$ current.

$P y$-GC/MS Analysis was carried out on an Agilent 5973N gas chromatograph equipped with a Frontier PY-2020iD Double-Shot vertical furnace pyrolyzer fitted with an AS-1020E Auto-Shot autosampler. The GC was coupled to a $5973 \mathrm{~N}$ single quadrupole mass selective

Table 1 List of samples with corresponding descriptions and sampling sites (samples S7 and S9 are missing due to sample misnumbering)

\begin{tabular}{|c|c|c|}
\hline Number & Description & Location \\
\hline S1 & Scraping of corrosion products & Inner portion of mantle at bottom, below proper right hand \\
\hline S2 & Scraping of corrosion products & Inner portion of coat at proper left \\
\hline S3 & Scraping of organic coatings & Area underneath telegraph, below proper left thumb \\
\hline S4 & Scraping of corrosion products & Inner portion of mantle at lower proper right \\
\hline S5 & Scraping of corrosion products & Inner portion of mantle in between legs \\
\hline S6 & Scraping of corrosion products & Inner portion of mantle at lower proper right \\
\hline S8 & Scraping of corrosion products & Inner portion of coat at proper right \\
\hline S10 & Scraping of corrosion products & Area above proper left knee at front \\
\hline S11 & Scraping of corrosion products & Area from proper right thigh at front \\
\hline S12 & Fragment of metal alloy for cross section & Area of internal crease of the mantle at top back \\
\hline S13 & Scraping of corrosion products & Surface of pedestal, proper left front corner \\
\hline S14 & Scraping of corrosion products & Area of proper left coat, above first button \\
\hline S15 & Scraping of corrosion products & Area of coat, over proper left shoulder blade at back \\
\hline
\end{tabular}


detector (MSD). Two samples of 30-50 $\mu$ g were weighed out in deactivated pyrolysis sample cups (PY1-EC80F Disposable Eco-Cup LF) on a Mettler Toledo UMX2 Ultra microbalance. Samples were then either pyrolyzed without derivatization or derivatized with tetramethyl ammonium hydroxide (TMAH) before pyrolysis. Derivatization took place in the same cups as follows: $3-4 \mu \mathrm{l}$ of $25 \%$ TMAH in methanol (both from Fisher Scientific), depending on the sample size, were added directly to the sample in each cup with a $50-\mu \mathrm{L}$ syringe and, after $1 \mathrm{~min}$, loaded onto the autosampler. The interface to the GC was held at $320{ }^{\circ} \mathrm{C}$ and purged with helium for $30 \mathrm{~s}$ before opening the valve to the $\mathrm{GC}$ column. The samples were then dropped into the furnace and pyrolyzed at $550{ }^{\circ} \mathrm{C}$ for $30 \mathrm{~s}$. The pyrolysis products were transferred directly to a DB-5MS capillary column $(30 \mathrm{~m} \times 0.25 \mathrm{~mm} \times 1 \mu \mathrm{m})$ with the helium carrier gas set to a constant linear velocity of $1.5 \mathrm{~mL} / \mathrm{min}$. Injection with a 30:1 split was used, in accordance with the sample size. The GC oven temperature program was: $40{ }^{\circ} \mathrm{C}$ for $1 \mathrm{~min} ; 10{ }^{\circ} \mathrm{C} / \mathrm{min}$ to $320^{\circ} \mathrm{C}$; isothermal for $1 \mathrm{~min}$. The Agilent 5973N MSD conditions were set as follows: transfer line at $320^{\circ} \mathrm{C}$, MS Quad $150^{\circ} \mathrm{C}$, MS Source $230^{\circ} \mathrm{C}$, electron multiplier at approximately $1770 \mathrm{~V}$; scan range 33-550 amu. For samples run with TMAH, the detector was turned off until 3 min to avoid saturation by excess of derivatizing agent and solvent. Data analysis was performed on an Agilent MSD ChemStation D.02.00.275 software by comparison with the NIST 2005 spectral libraries.

$p X R F$ Analysis was conducted non-invasively using an Elio XGLab energy dispersive XRF analyzer, with a high resolution large area Silicon Drift Detector (SDD) with $130 \mathrm{eV}$ at manganese (Mn) Ka with $10 \mathrm{kcps}$ input photon rate (high resolution mode), $170 \mathrm{eV}$ at $\mathrm{MnK} \alpha$ with $200 \mathrm{kcps}$ input photon rate (fast mode). The system is equipped with changeable filters, and a rhodium (Rh) transmission target with $50 \mathrm{kV}$ maximum voltage and $4 \mathrm{~W}$ maximum power. The size of the analyzed spot is $1 \mathrm{~mm}$, and analyses were collected for $60 \mathrm{~s}$ live time, setting the voltage at $40 \mathrm{kV}$ and the current at $50 \mathrm{~mA}$.

$S E M / E D S$ Analysis of a cross section of the metal alloy was performed with a FE-SEM Zeiss $\Sigma$ igma HD, equipped with an Oxford Instrument X-MaxN 80 SDD detector. Back-scattered electron (BSE) imaging, energydispersive spectroscopy (EDS), and X-ray mapping were performed in high vacuum with an accelerating voltage of $20 \mathrm{kV}$, on the cross section mounted on an aluminum stub and coated with a 14-nm layer of carbon, at a working distance of $8.5 \mathrm{~mm}$. For measurements on the metal alloy, a standardless quantification was selected and semi-quantitative data were processed with the AZtec software, using automatic background subtraction, matrix correction, and normalization to $100 \%$ for all the elements in the peak identification list.

Laser cleaning equipment The goals of laser cleaning were to safely remove the degraded lacquer coating and the active corrosion condition from the recessed surfaces of the figure's long coat. Cleaning was accomplished using a GC-1 laser cleaning equipment manufactured by G. C. Laser Systems Inc. of Chicago, Illinois. This system, equipped with solid state, air-cooled 1064-nm wavelength laser, was selected for its precision, relative speed and safety, environmental consciousness, and tuning capability that optimizes cleaning and limits the potential for damage. In the recent past, lasers' scan patterns had been limited to a minute spot and/or a horizontally orientated line. The GC-1 laser employs a new and unique handheld, circular scanning pattern, which emits pulses through fiber optic to a surface being cleaned in a circular, rotating pattern. A helpful description and illustration of the new scan pattern technology is provided by Dajnowski and Dajnowski [15]. The GC-1 laser is unique in that it exploits tunable settings, a relatively recent innovation in the conservation of art. Among these tunable operating parameters are pulse energy $(0-1 \mathrm{~mJ})$, revolutions per minute of the circular scanning pattern (3000-12,000 RPM), pulse frequency ( $1 \mathrm{kHz}-1 \mathrm{MHz})$, and pulse duration (10-520 ns). The latter has been shown to be the most crucial setting; when optimized, longer pulse duration improves selectivity and precision in cleaning and controls photothermal and photomechanical shock due to lower peak energy delivered at a certain range of fluence (energy delivered per unit area) $[5,16]$. Preliminary tests were performed on the sculpture by consulting conservators with G. C. Laser Systems Inc., including the equipment's developer. Their extensive previous experience in removing lacquer coatings and corrosion on historic figurative bronzes was key to establish the appropriateness of the methodology and operating parameters for the treatment $[3,17]$. A class 4 laser safety area (LSA) with ample site controls and warning signage was configured inside Central Park's conservation workshop. Two overhead hoists permitted the over $1500-\mathrm{lbs}(680-\mathrm{kg})$ figure to be laid down and manipulated during treatment, providing access to recessed surfaces for optimal laser cleaning and outfitting with new bronze mounting hardware for reinstallation on its granite base. The LSA consisted of a $12^{\prime} \mathrm{H} \times 18^{\prime} \mathrm{L} \times 12^{\prime} \mathrm{D}$ (about $3.66 \mathrm{~m} \times 5.49 \mathrm{~m} \times 3.66 \mathrm{~m}$ ) opaque, curtained enclosure to prevent accidental viewing from outside during laser operation. A Nederman modular gas and vapor carbon filtration system, outfitted with a \#12603461 replacement filter and a 1.5 HP NIB 2001 model blower/fan run on $110 \mathrm{~V} \mathrm{AC}$, was used to capture fumes generated by the ablated materials. The handheld laser unit is provided 
with interchangeable focal length lenses (i.e. 10-, 16-, 25 -cm focal length) that operate/ablate only in their designated focal zone. Overall laser cleaning of the surface employed a $16-\mathrm{cm}$ focal length lens, with pulse duration in the $240-270-n s$ range, $70-\mathrm{kHz}$ pulse frequency at a range of $90-100 \%$ laser power (maximum laser power $70 \mathrm{~W}$; maximum energy per pulse $1 \mathrm{~mJ}$ ), and 9000$12,000 \mathrm{RPM}$. Fluence was delivered at a range of 3-5.66 J/ $\mathrm{cm}^{2}$. Selective, increasingly aggressive cleaning of blisters of active bronze corrosion in recesses employed a $10-\mathrm{cm}$ focal length lens fired at $270-\mathrm{ns}$ pulse duration at $70-\mathrm{kHz}$ pulse frequency, using 100\% laser power and 5000 RPM, with fluence delivered at a maximum of $19.9 \mathrm{~J} / \mathrm{cm}^{2}$.

\section{Results and discussion}

Preliminary visual examination of the Morse sculpture enabled conservators to identify the main ongoing conservation issues, which were mostly related to corrosion and to the presence of one or more degraded organic coatings. Over time, the statue's surface has suffered from severe corrosive attack. Pitting and loss of sculptural surface details (Fig. 2) were caused by the exposure to atmospheric pollutants such as acid rain and chlorides from deicing salts and the marine environment, in addition to dry deposition of biogenic and anthropogenic pollutants such as $\mathrm{NO}_{2}, \mathrm{SO}_{2}$, and carboxylic acid.
The exposed surfaces have remained stable since being regularly treated with cleaning interventions and protective coatings beginning in the 1990s. However, localized patches of virulent, irregularly shaped pustules of active corrosion were contributing to progressive surface loss (Fig. 3a) and associated coating failure (Fig. 3b) in the deep recesses of the figure's long cloak. The surfaces within the recesses are so well protected that they do not benefit from washing during typical rain events or associated run off. Morse's sculptural geometry may explain the localization of corrosion phenomena in those recessed and protected locations where elevated chloride concentration accelerates surface loss [18]. The aged and degraded coating was otherwise admitting moisture and corrosive agents directly onto the bronze substrate, and was no longer providing adequate protection to the sculpture.

\section{Analysis of organic coatings}

The organic coating was investigated to determine its constituent materials and the possible presence of pigments. In order to do so, a sample (S3) was removed from an area of the sculpture underneath the telegraph, below the figure's proper left thumb, and analyzed by Py-GC/MS. All chromatograms obtained with and without TMAH derivatization appeared to contain series
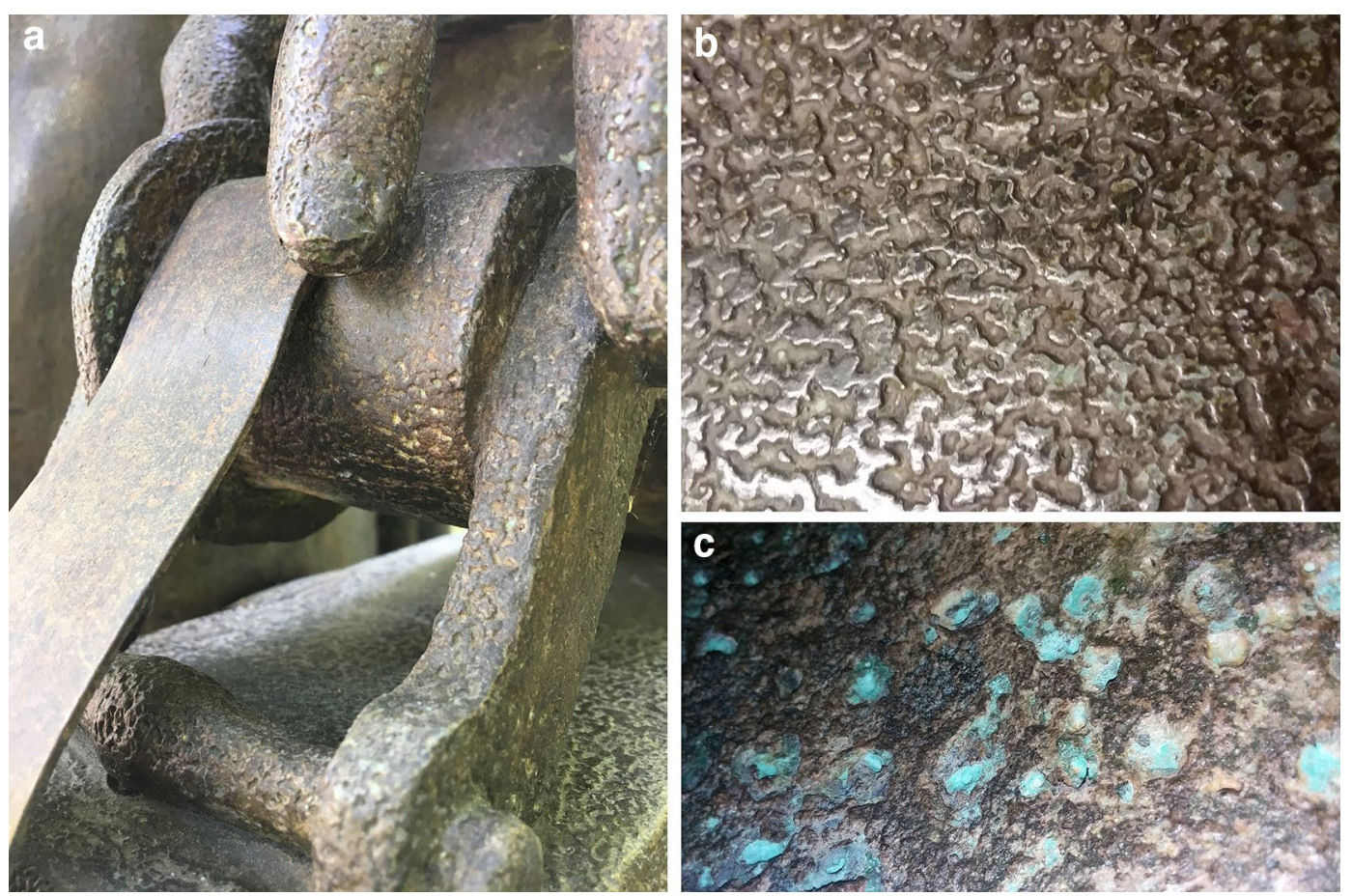

Fig. 2 Condition issues observed on the Morse sculpture (I). Photographs showing (a) a detail of sculptural surface loss, (b) typical pitting and loss pattern on exposed surfaces, and (c) a detail of active corrosion present in the recessed areas 

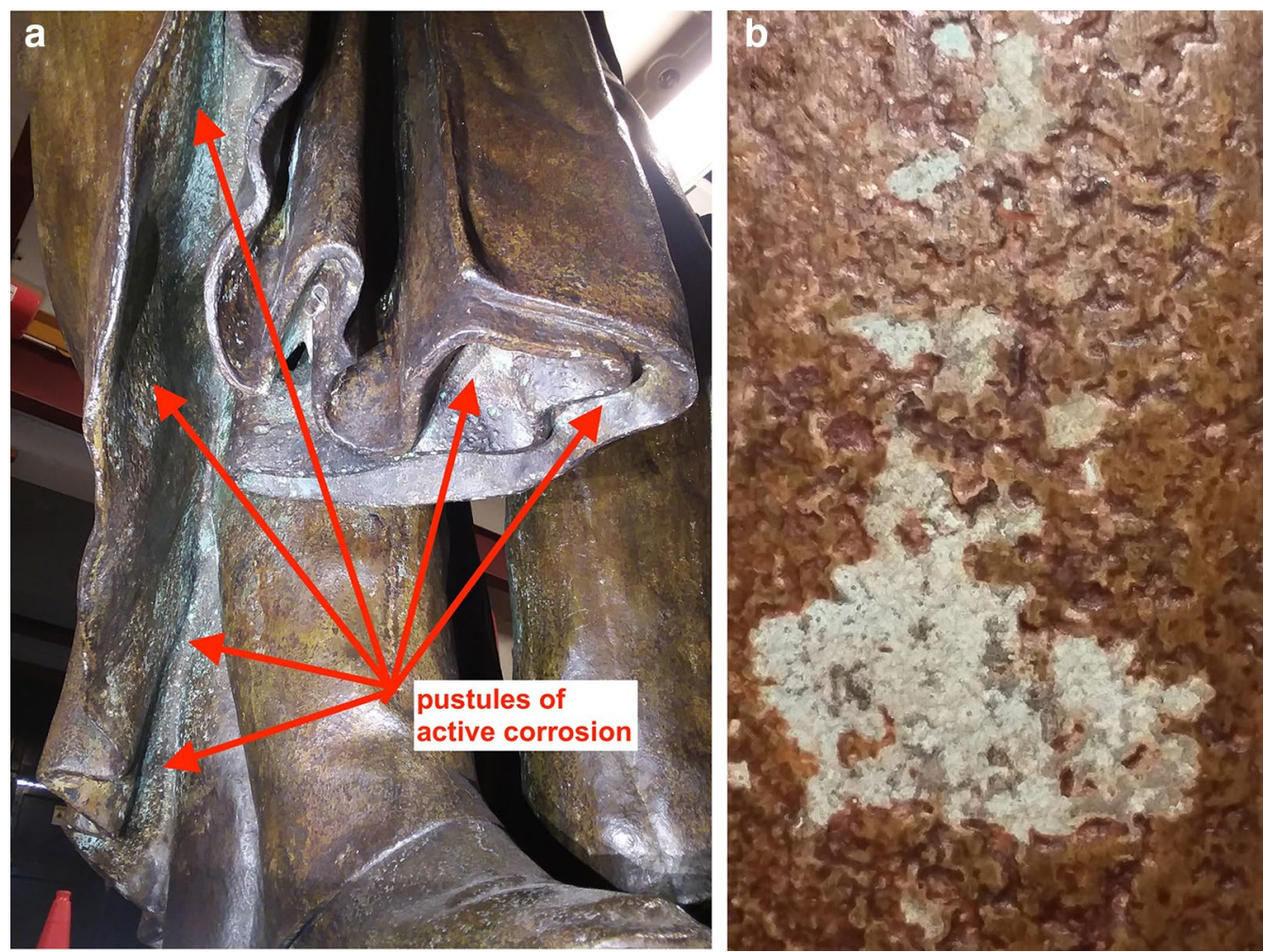

Fig. 3 Condition issues observed on the Morse sculpture (II). Photographs showing (a) the extent of active corrosion in the protected recesses of the figure's long coat, and (b) a detail of toned coating failure and underlying patina

of alkanes organized in a specific distribution that is characteristic of mineral waxes (Fig. 4). From a conservation perspective, mineral waxes are known for having a limited lifetime, ranging from 2 to 5 years, and for being reversible [19]. Bronzes coated with wax are easily cleaned with water, which makes wax suitable for a low cost and low maintenance application. However, the sample examined was found to contain also high relative amounts of acrylics, mostly methyl methacrylate and acrylic acid ethyl ester. The presence of these compounds is consistent with the use of Incralac ${ }^{\circledR}$ [20], which is, in fact, a product commonly used in the past and reported to have been applied to the Morse statue in the early 1990s according to the available conservation records [21]. Acrylic coatings have a longer lifetime compared to mineral waxes, and they also show good reversibility properties [19]. Acrylic lacquers are coupled with a sacrificial wax topcoat that is renewed yearly in the case of Morse. Since 2003, two types of cyclically renewable wax topcoats have been used by CPC's conservators: (1) Boston Polish $^{\mathrm{TM}}$, also known as "butchers" paste wax, a carnauba-based wax, in use from 2003 to 2006; (2) Renaissance microcrystalline wax $^{\mathrm{TM}}$, a mixture of Cosmoloid H80 and BASF A wax [22, 23], used from 2007 to

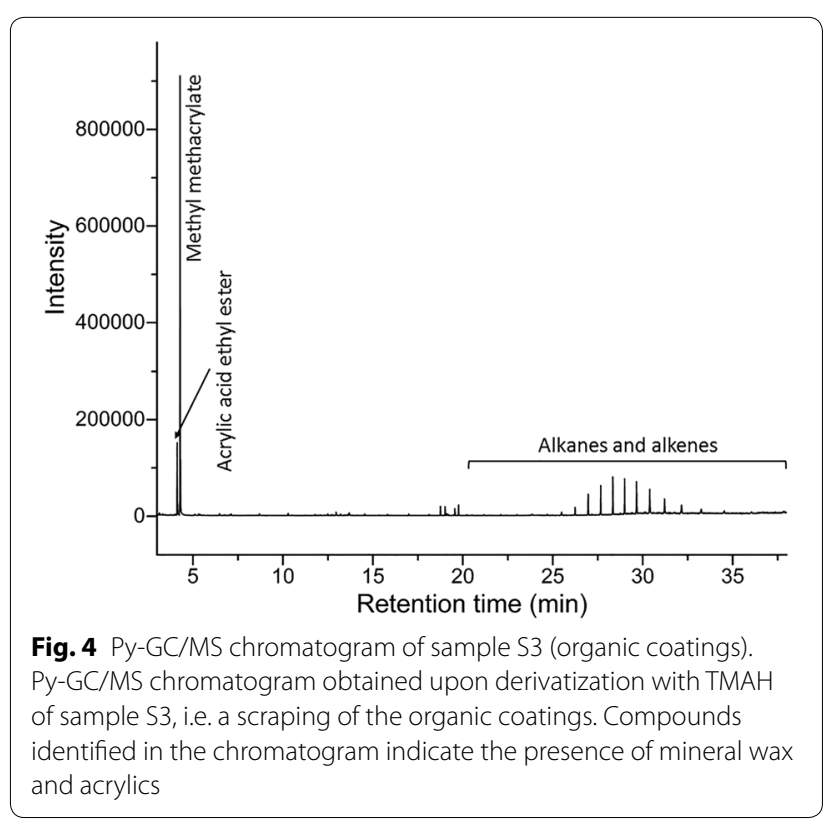


date for protecting outdoor bronze sculptures in Central Park.

In terms of coloring, verbal accounts and visual observation suggested that the Morse sculpture might have been coated with pitch at some early stage, although there are no written records of this intervention. The color of organic coatings in bronze sculptures is also sometimes obtained through the addition of bitumen, which might lend the coating a dark or brown hue [24]. Accordingly, visual inspection indicated that, possibly, very low amounts of pitch or bitumen residues may have been present on the back of the bronze, although, in this case, no samples were removed to verify this hypothesis, given the small dimension of the areas in question and in order to preserve the sculptures' integrity and appearance. However, an unexpectedly high amount of iron (Fig. 5, before cleaning) was detected by pXRF analysis on several locations of the surface still covered by the organic coatings, suggesting the use of iron oxide/hydroxide pigments as coloring agents in the acrylic layer. Comparisons with spectra collected on areas of bare metal confirmed the exclusive presence of iron, and the absence of other elements, in such organic layer.

\section{Analysis of corrosion products}

In areas of the Morse sculpture that were less exposed to the atmospheric agents and not covered by the protecting coatings, various shades of green corrosion products were observed and sampled for analysis. XRD detected several compounds mostly attributable to the following categories: sulfates, sulfides, chlorides, and oxides. The hydrous copper sulfate mineral antlerite $\left(\mathrm{Cu}_{3}\left(\mathrm{SO}_{4}\right)\right.$ $\left.(\mathrm{OH})_{4}\right)$, found in all samples examined, appears to be the main sample constituent among those present, sometimes in association with minor amounts of copper trihydroxichlorides such as atacamite or clinoatacamite $\left(\mathrm{Cu}_{2}(\mathrm{OH})_{3} \mathrm{Cl}\right)$, as in the case of samples $\mathrm{S} 1, \mathrm{~S} 2, \mathrm{~S} 4$, and S5. In addition, brochantite $\left(\mathrm{Cu}_{4} \mathrm{SO}_{4}(\mathrm{OH})_{6}\right)$ and cuprite $\left(\mathrm{Cu}_{2} \mathrm{O}\right)$ were identified in samples $\mathrm{S} 5$ and $\mathrm{S} 7$, the latter also containing copper sulfide and gypsum (Fig. 6). All these compounds are described in the literature as products commonly associated to bronze disease, affecting copper alloys [25-29]. However, no traces of nantokite $(\mathrm{CuCl})$, the main compound responsible for bronze disease, were detected in any of the samples analyzed. For this reason, the presence of copper trihydroxichlorides on this sculpture may be attributed to a harmful superficial corrosion process, either originating from the reaction of copper with water or as a result of its interaction with atmospheric pollutants (leading to the formation of chlorides and brochantite, respectively).

Antlerite is frequently found as a main constituent of patinas in outdoor sculptures [30], while less common might appear the finding of chlorides. Due to the decrease of rainwater $\mathrm{pH}$ since the mid-20th century, antlerite also became a widespread component of corrosion crusts, mainly in partially exposed or sheltered surfaces [28]. Robbiola and coworkers [19] observed that brochantite often transforms into antlerite in outdoor sculptures, hypothesizing that the low $\mathrm{pH}$ of rainwater might be the enhancing factor of this reaction. However, it has been demonstrated that the degradation of bronze outdoor sculptures was more affected by dry deposition rather than acid rain in the 1980s [1]. In New York City, levels of $\mathrm{SO}_{2}$ have constantly decreased especially in the last decade [31], with the consequence that dry deposition should no longer have substantial effects, while corrosion rates are expected to return to pre-industrial levels in the future [1].

Considering that Central Park is relatively close to the ocean and therefore subjected to its atmospheric corrosion environment, and, above all, taking into account the enormous amount of roadway ice melting salts distributed on the roads during wintertime, the detection of copper chlorides on the Morse statue should not surprise. The sculpture had originally been sited on the Mall in Central Park, a pedestrian promenade, where it remained for more than 100 years. In 1988, the statue was moved to its current location at the East 72nd Street entrance to the Park on the South side of the Drive roadway and in proximity to Fifth Avenue, where the exposure to ice melting salts is substantial during the winter months. In fact, chloride ions that separate from sodium as the ice melts are extremely corrosive. It seems plausible that the water enriched with these ions could become aerosolized by the constant traffic whisking by and deposited onto the bronze. Thickett and coauthors $[22,23]$ have demonstrated that water may be retained at the interface between the superficial layer of Renaissance wax and the coating underneath, further enhancing the corrosive attack. On ferrous metals, like steel, the prolonged exposure to this trapped moisture after the protective period of the coating might increase the rate of corrosion. A similar process cannot be ruled out for copper-based alloys.

\section{Monitoring of laser cleaning}

To evaluate the distribution and thickness of the various corrosion layers within the sculpture's stratigraphy, and to determine the exact composition of the metal alloy, a small sample (S12) removed from the rear of the Morse statue was mounted as a cross section and analyzed by SEM/EDS (Fig. 7). Results on the composition of the sculpture's constituting copper alloy (layer 1), calculated by means of EDS, are reported in Table 2. In detail, the relative amounts of copper $(\mathrm{Cu})$ and tin $(\mathrm{Sn})$ 
Basso et al. Merit Sci

(2020) 8:81

Page 8 of 14
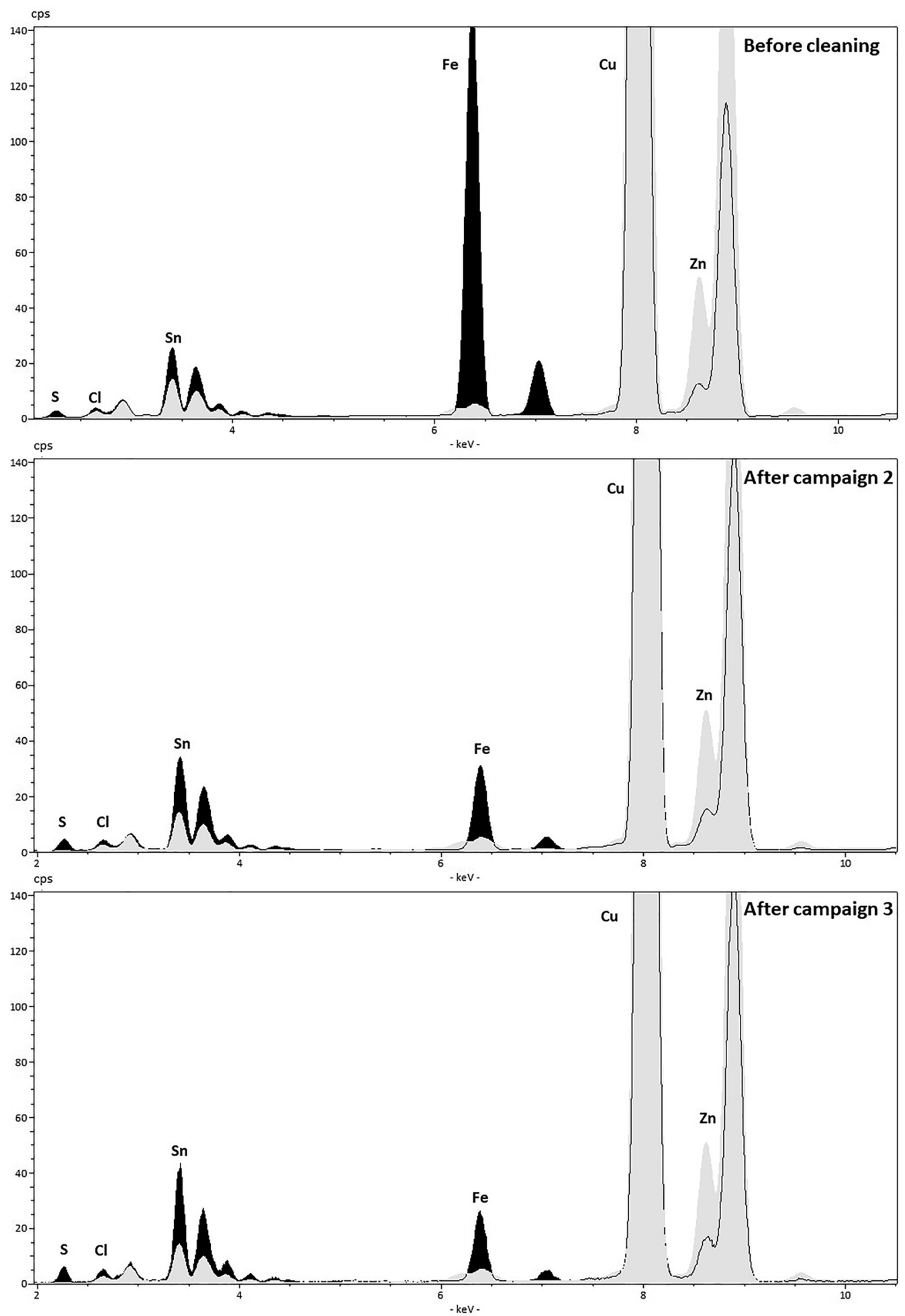

Fig. 5 XRF spectra acquired to monitor the laser cleaning. Examples of XRF spectra collected from the Morse statue before laser cleaning ( $p X R F$ campaign 1; black pattern) and during laser cleaning (pXRF campaigns 2 and 3; black pattern). A reference spectrum acquired from an area of bare metal (gray pattern) is also reported in each graph for comparison. The data shows a progressive decrease in the intensity of the iron peak after subsequent treatment phases 

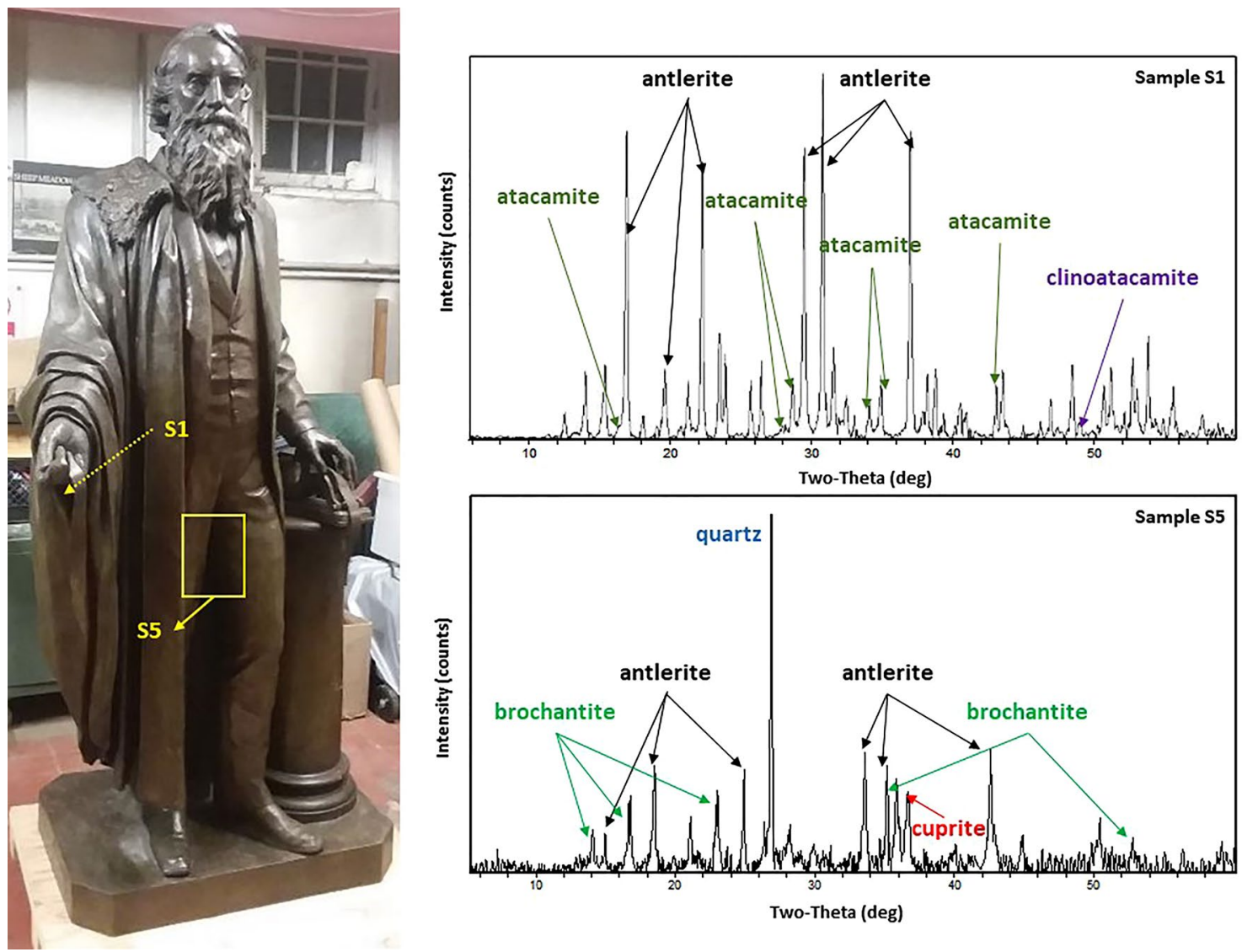

Fig. 6 XRD patterns of samples S1 and S5 (corrosion products). XRD patterns of samples S1 and S5, i.e. two scrapings of corrosion products, with their respective sampling locations

detected, alongside the observed zinc (Zn) content, are consistent with the composition of a ternary alloy and are very similar to gunmetal bronze (also known in the United States as red brass). This alloy was first identified in a 13th-century English memorial sculpture and later used for casting cannon. Its utilitarian characteristics include ease of casting in detail, toughness, resistance to corrosion, and machinability. The frequent use of this alloy to cast statuary in the United States in the mid-19th century may be attributed to the prevalence of the English emigrant group and its craft traditions, or possibly to an expedient coincidence. For instance, the Ames Manufacturing Company of Chicopee, Massachusetts, is a prominent example of an American foundry concurrently producing military ordnance and "bronze" statuary during that period.

EDS analysis showed the additional presence, in the sculpture's ternary alloy, of small particles of less than $10 \mu \mathrm{m}$ in size, with irregular shapes, scattered throughout the metal matrix, which were identified as zinc sulfides (Fig. 8). These compounds appear to be sometimes associated with copper sulfides. Exact compositions of both zinc and copper sulfides are reported in Table 2. Regarding the pitting phenomenon also observed in the Morse sculpture, one must consider that the presence of pits in copper-based alloys is often related to the dezincification of the alloy [28]. Here, however, this hypothesis is unlikely, as red brass displays less of a proclivity for this type of deterioration than other alloys, in particular when protected by a thin layer of copper oxides, such as cuprite [32]. In the present case, analysis of the corrosion layers shows a clear transition from an underlying cupritebased layer to a more superficial region that is mostly composed of copper sulfates, as indicated in Fig. 7. The first corrosion layer observed (layer 2, Fig. 7), showing red in the optical microscopy image, was found to be mainly composed of cuprite and enriched in tin. A second corrosion layer (layer 3, Fig. 7) above that, appearing green under polarized light, is characterized by the presence of copper sulfates and is richer in tin than layer 2. Traces of an additional, very thin, green corrosion layer (layer 4, Fig. 7), which contains a mixture of copper chlorides 

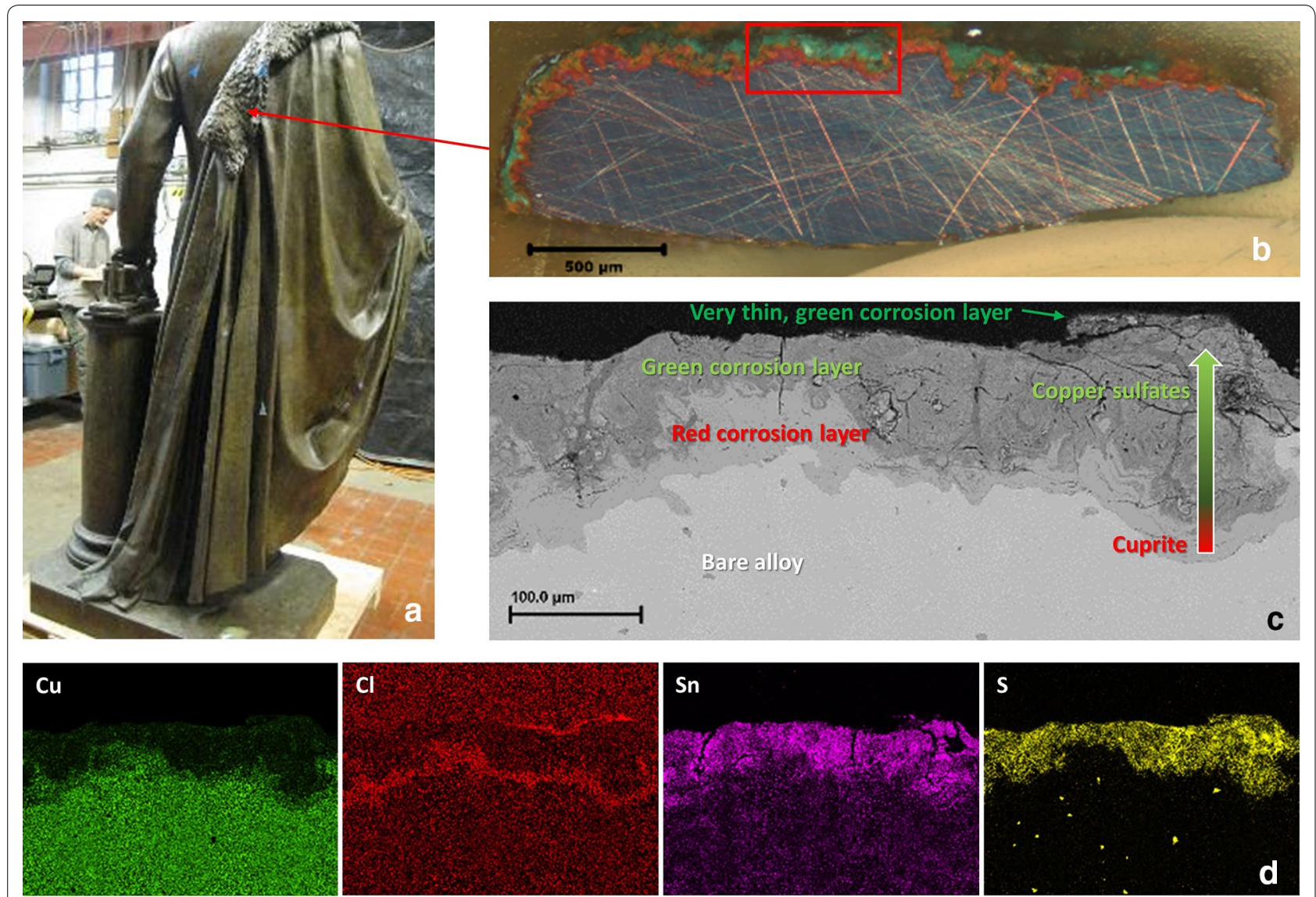

Fig. 7 Optical microscopy, BSE images, and X-ray elemental maps of cross section S12 (metal alloy and corrosion products). a Image of the Morse sculpture in Central Park's conservation laboratory. The red arrow indicates a location on the statue from which a multi-layered sample was removed for analysis of the metal alloy and corrosion products (sample S12). b Polarized light micrograph of sample S12 mounted as a cross section. c BSE image of the portion of sample $\mathrm{S} 12$ indicated by a red square. The red and green arrow indicates changes in composition within the stratigraphy when moving from the main metal alloy up to the surface. $\mathbf{d}$ X-ray elemental maps of copper (Cu), chlorine (Cl), tin (Sn), and sulfur (S) collected from a portion of cross section $\mathrm{S} 12$

Table 2 SEM/EDS data and expressed as normalized wt\%. Numbers within brackets refer to layers in Fig. 7

\begin{tabular}{|c|c|c|c|c|c|c|c|c|c|c|c|c|c|c|}
\hline & $S$ & $\mathrm{Fe}$ & $\mathrm{Cu}$ & Sn & $\mathrm{Zn}$ & $\mathrm{SiO}_{2}$ & $\mathrm{Al}_{2} \mathrm{O}_{3}$ & $\mathrm{~K}_{2} \mathrm{O}$ & $\mathrm{P}_{2} \mathrm{O}_{5}$ & $\mathrm{SO}_{3}$ & $\mathrm{Cl}$ & $\mathrm{FeO}$ & $\mathrm{CuO}$ & $\mathrm{SnO}_{2}$ \\
\hline Bare alloy (1) & & & 91.0 & 6.4 & 2.6 & & & & & & & & & \\
\hline Red corrosion layer (2) & & & & & & & & & & 0.8 & 1.0 & & 85.5 & 12.5 \\
\hline Green corrosion layer (3) & & & & & & 0.2 & & & 0.3 & 18.1 & 0.1 & 0.5 & 55.8 & 25.1 \\
\hline $\begin{array}{l}\text { Very thin green } \\
\text { corrosion layer (4) }\end{array}$ & & & & & & 1.6 & 0.9 & 0.2 & 0.3 & 23.5 & 2.2 & 0.5 & 70.3 & 0.6 \\
\hline Copper sulfide particle & 21.4 & 0.2 & 78.4 & & & & & & & & & & & \\
\hline Zinc sulfide particle & 33.1 & 0.3 & 4.4 & & 62.2 & & & & & & & & & \\
\hline Zinc sulfide particle & 32.9 & 0.6 & 5.7 & 0.3 & 60.5 & & & & & & & & & \\
\hline Zinc sulfide particle & 33.1 & 0.4 & 4.2 & 0.2 & 62.1 & & & & & & & & & \\
\hline Zinc sulfide particle & 34.1 & 0.5 & 4.9 & & 60.6 & & & & & & & & & \\
\hline Zinc sulfide particle & 33.6 & 0.4 & 4.0 & & 62.0 & & & & & & & & & \\
\hline
\end{tabular}




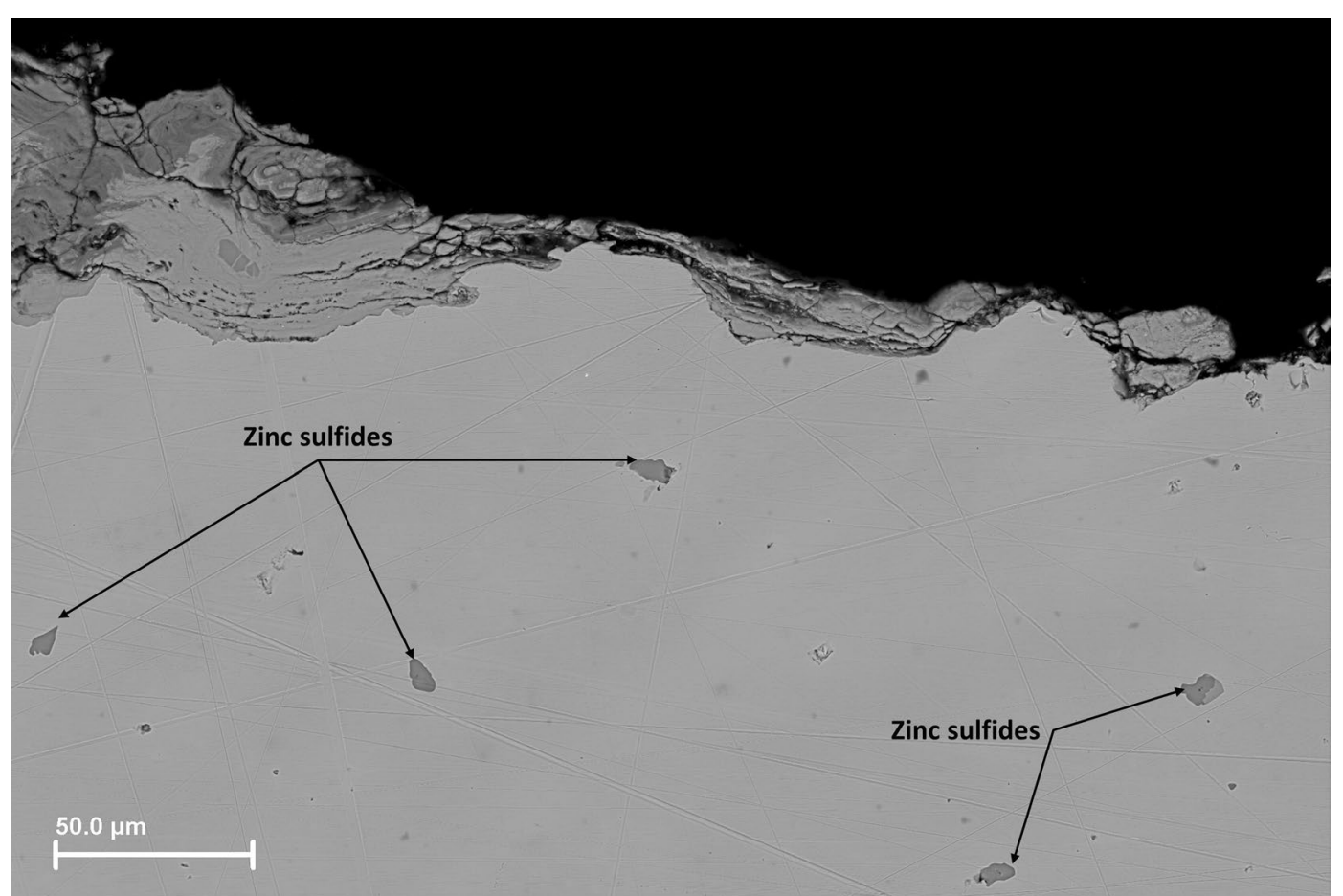

Fig. 8 BSE image of zinc sulfides in sample S12 (metal alloy and corrosion products). BSE image of a portion of cross section S12, showing the presence of sparse zinc sulfide inclusions in the metal alloy

and dirt, are still visible on the surface. These data suggest that the corrosion process might have induced a preferential dissolution of copper and zinc linked to the presence of oxygen within the whole thickness of the corroded layer, as shown by the X-ray elemental maps of copper $(\mathrm{Cu})$, chlorine $(\mathrm{Cl})$, tin $(\mathrm{Sn})$, and sulfur $(\mathrm{S})$ within the corrosion layer (Fig. 7d). In outdoor conditions, the initial formation of a reddish-brown layer of cuprite is typically followed by the formation of different additional compounds, as also confirmed in the present study: copper basic sulfates, such as antlerite and brochantite, can be found on bronzes exposed in urban environments, while copper hydroxychlorides, such as atacamite and paratacamite, are usually formed in chloride-rich environments [9 and references therein].

An additional goal of the present study consisted in monitoring the laser cleaning intervention on the Morse statue by qualitatively analyzing the surface elemental composition before (pXRF campaign 1) and during (pXRF campaigns 2 and 3 ) the process (Fig. 5). To achieve this goal, analysis was repeatedly carried out on eighteen select locations prior to cleaning and throughout a few subsequent phases of treatment to monitor changes on the target areas. Following a comparison between measurements recorded on the sculpture's external surface and reference ones collected on areas of bare metal on the pedestal, sulfur $(\mathrm{S})$, chlorine $(\mathrm{Cl})$, and iron $(\mathrm{Fe})$ were selected as the ideal candidate elements to monitor the progress of the laser cleaning. These elements, in fact, are considered respectively indicative of the presence of sulfates and sulfides (e.g. antlerite, brochantite, copper sulfides), chlorides (e.g. atacamite, clinoatacamite, paratacamite), which are the main corrosion products constituting the patina, as well as the coating, whose brown color, as explained above, is likely due to iron-containing pigments.

Following the initial phase of the cleaning, pXRF measurements showed relatively high levels of iron in all the spots analyzed, with the exception of a reference reading collected from an area of bare metal. Iron tends to decrease from measurements acquired during pXRF campaign 1 to those recorded in campaign 2, while it is found in trace amounts on the uncoated bronze (Fig. 5). This likely indicates that the occurrence of this element might be limited to the superficial organic coating, and, therefore, associated with the presence of iron oxide/ hydroxide pigments in such coating, as mentioned earlier. Minor amounts of lead were also detected on locations yet to be cleaned, with a noticeable decrease in 
spectra collected upon treatment during campaign 2 . This observation, along with the absence of lead in the reference measurements acquired from the bare metal, suggests that this element, whose presence was limited to the uppermost portion of the sculpture's stratigraphy and thus attributable to external causes, may be interpreted as a residue of the atmospheric pollution deposition. Interestingly, the amount of greenish corrosion products, namely chlorine-based and sulfur-based compounds, was found to decrease upon initial lasering, while an increase followed by a small decrease was noted following the second and third phases of treatment. The increased concentrations of chlorine and sulfur after cleaning phase 2 indicate that the laser cleaning performed up until that point might have exposed a deeper portion of the corroded layer (Fig. 5). Another possible explanation for the observed increase of these elements' peak intensity might lie in the practice of misting the sculpture with distilled water after each lasering session. This process activates entrained chlorides and precipitates them onto the surface, from which they are ablated in subsequent cleaning sequences. As initial pXRF analyses were carried out after misting but before the following cleaning, it is plausible that re-precipitated chlorides were measured. A final phase of overall laser cleaning was applied to add variance of the laser's angle of attack. This was especially important for eradicating loose corrosion in the deeply pitted areas where minute undercuts partially obscured direct access to those surfaces. The goal of this additional cleaning step was to further reduce the presence of powdery corrosion products and tenaciously adhered coating residue that may negatively affect proper adhesion of the new coating.

\section{Additional conservation treatment}

As some of the Morse statue's surfaces were not easily accessible for laser cleaning, an additional treatment using propane-fueled torches to heat the surface and volatilize the remnant coating and corrosion products was performed in the deepest pits and recesses of the sculpture. Following the technical guidelines of the U.S. General Services Administration [33], two applications of benzotriazole (BTA), an effective corrosion inhibitor, were selectively applied on the undercuts and recesses where pustules had formed in an attempt to stabilize the surface from further loss by arresting or eradicating propagation of the condition. BTA reacts with corrosion products such as cuprite and copper trihydroxychlorides to form $\mathrm{Cu}(\mathrm{I}) \mathrm{BTA}$ and $\mathrm{Cu}(\mathrm{II}) \mathrm{BTA}$ copolymers, resulting in an optimal and stable coating that ensures durability of the artwork [34]. The double application of BTA, guaranteed thorough coverage in recessed areas, ensured complete reaction of this chemical with all the remaining available unstable compounds that were not complexed during the first application. After application of BTA, the treated area was cleaned with soft bronze bristle brushes and allowed to dry. The resulting precipitate matter was then flushed clear and the surfaces thoroughly rinsed with distilled water. After that, the sculpture was carefully wet-steam pressure washed to remove any remaining residue. On the undersides and recesses of the long coat, i.e. the location most affected by bronze corrosion, the patina had been removed completely by laser ablation, exposing the bare bronze. Apart from this area, complete removal of the corrosion layers was outside the scope of the present project.

In terms of coloration, a selective application of cupric nitrate and cupric chloride patina solutions to achieve a range of green, and of ammonium sulfate for darker brown in the recesses of the long coat, was used to blend and unify tone and to enhance legibility of the sculptural forms. Finally, a translucent, warm brown coating that established a contiguous protective film and accentuated nuances of the underlying greenish patina was applied as the new finish (Fig. 9). To produce the desired effect, a small sample of the previous coating had been retained on the figure's long coat for matching in situ. Swatches of toned lacquer were applied beside it to approximate the tone and translucency. Members of New York City Design Commission's Conservation Advisory Group (CAG) reviewed the mock-ups and approved of a sample, which was sent to the manufacturer for matching using a BYK Instruments colorimeter (catalog \#6830). The identification of iron-containing pigments to color the lacquer finish guided the decision of applying a new coating containing the same type of coloring materials. The Conservancy emphasizes environmental excellence in its management and operations and, hence, a coating product with proven performance that was in alignment with the organization's mission was required [35]. Such lacquer, selected from Nikolas Coatings of Chicago, Illinois, is a low volatile organic compound (VOC) anti-corrosion base mixture that was custom matched and renamed for this project (\#15794 Morse brown toner RFU; $317.13 \mathrm{~g} / \mathrm{L}$ VOCs). Increased VOCs are associated with harmful effects from ground-level ozone and their reduction is a public health benefit [36]. The solvent-borne coating is a chemical mixture of parachlorobenzotrifluoride $50-60 \%$, acetone $20-30 \%$, diisobutyl ketone $1-5 \%$, xylenes $(o-, m-$, $p$-isomers) $1-5 \%$, and ethyl alcohol $0.10-1 \%$ by weight concentration; with solids content of $5-10 \%$ acrylic resin (proprietary), and iron oxide pigment admixture of 3-5\% yellow \#42, $0.01-0.05 \%$ red \#101, and 1-3\% standard carbon black. BTA is added into the coating mixture 3\% by weight. The new toned lacquer achieved various project goals including obtaining the desired visual nuance 


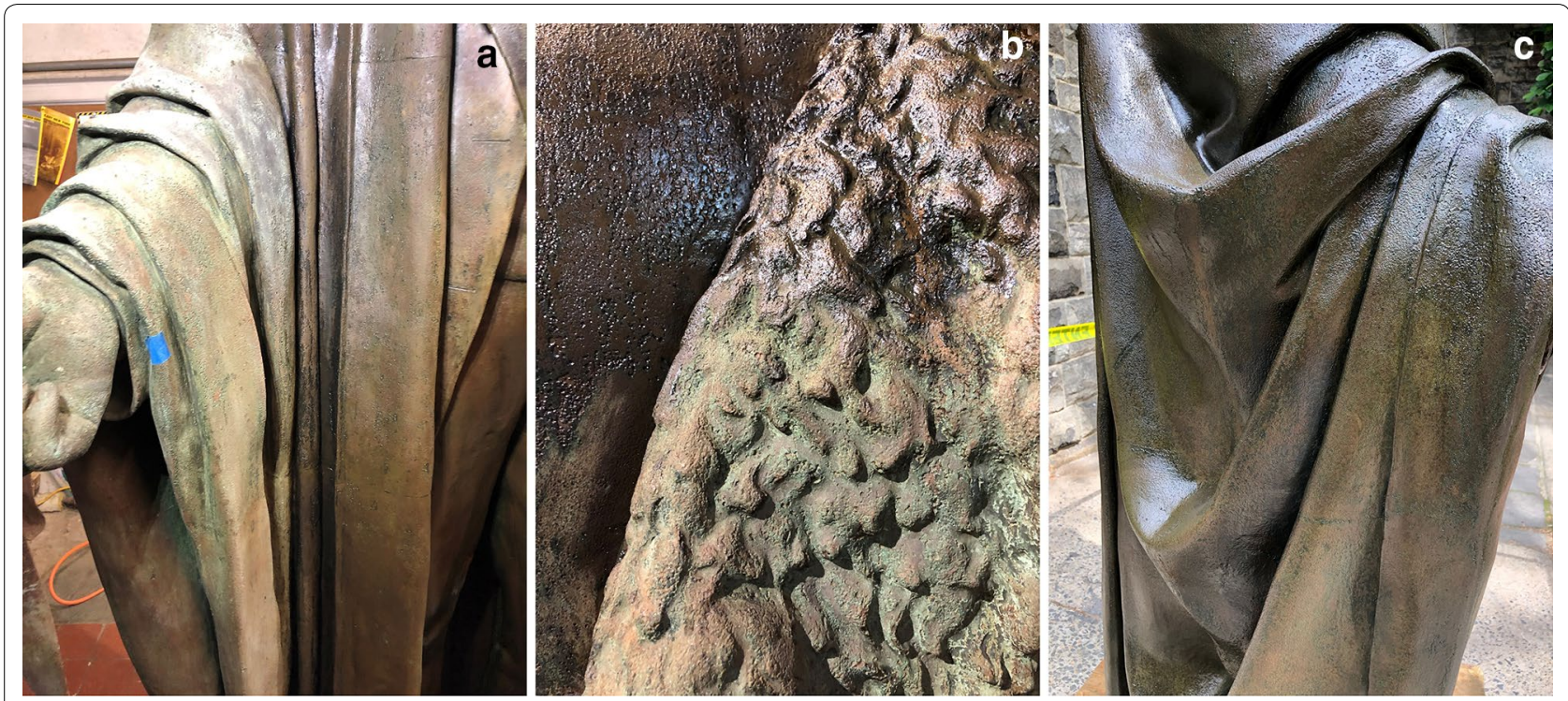

Fig. 9 Application of new coating. $\mathbf{a}$, $\mathbf{b}$ Details of the Morse statue photographed during the application of the new lacquer coating, including coated and uncoated areas. It is worth noting the contrast between the portion already brushed and the bare surface. c Final visual effect upon application of the new coating over the green patina, upon drying

for the finish, and the iron contained in it may increase electrical resistance, supplement barrier properties, and provide additional corrosion protection to the bronze [37]. The solvent-borne coating was thinned and brushapplied twice overall to assure penetration into the pitted texture of the Morse sculpture and to obtain complete coverage in deep recesses and undercuts. Three subsequent applications with a high volume-low pressure (HVLP) sprayer completed the coating.

\section{Conclusions}

The present study aimed to shed light on the materials, methods of fabrication, and ongoing condition issues of the Samuel F. B. Morse sculpture, located in Central Park, New York City. Special attention was paid to investigating the exact composition of the artwork's constituting metal alloy, the corrosion products affecting its surface, and the organic coatings that protect the bronze; to monitoring the progress and assess the effectiveness of the laser cleaning treatment through scientific analyses; and to informing present and future conservation strategies. Results of scientific analysis identified the main metal alloy of the sculpture as a copper ternary alloy very similar to gunmetal bronze. The primary corrosion products found on the Morse statue consisted of sulfates (e.g. antlerite, brochantite) and chlorides (e.g. atacamite, clinoatacamite, paratacamite), along with lower amounts of sulfides and oxides (e.g. cuprite). On the other hand, characterization of the organic coatings covering the surface revealed a combination of mineral wax and acrylics. Three analytical campaigns of pXRF were performed on target locations of the work to monitor the laser cleaning and demonstrated the treatment's effectiveness in removing selected residues and compounds. Results of scientific analysis, in particular, were crucial in guiding the formulation and optimization of a suitable conservation protocol tailored to the removal of atmospheric pollutant deposition, of the outdated organic coatings, and of the uppermost portion of the corrosion patina. Apart from the more critical bronze corrosion in the recesses of the figure's coat, however, complete ablation of the corrosion layers was outside the scope of this project. An additional consideration is that antlerite and brochantite are the most stable corrosion products among those identified, and as such they can play a beneficial role in preserving the current state of the artwork. Finally, the detection and identification of iron oxide/hydroxide pigments in the sculpture's organic coating guided a decision to replace it with a new translucent, brown-toned lacquer containing the same type of coloring materials in order to achieve the desired visual nuance for the finish and provide additional corrosion protection to the bronze.

\section{Abbreviations}

pXRF: Portable X-ray fluorescence spectroscopy; XRD: X-ray powder diffraction; SEM/EDS: Scanning electron microscopy with energy-dispersive $X$-ray spectroscopy; Py-GC/MS: Pyrolysis-gas chromatography/mass spectrometry.

\section{Acknowledgements}

The authors are indebted to Bartosz Dajnowski of G. C. Laser Systems Inc. and Andrzej Dajnowski of CSOS Inc. for their invaluable assistance with laser cleaning. The authors also want to express their gratitude to the three anonymous reviewers, whose comments helped improve the paper. 


\section{Authors' contributions}

EB performed XRD, SEM/EDS, pXRF, interpreted these data, and drafted the manuscript; FP helped with pXRF, performed Py-GC/MS and interpreted results, wrote the corresponding section of the article, and reviewed the whole manuscript; MR designed and performed all conservation treatments, and contributed to drafting the conservation-related section of the paper. All authors read and approved the final manuscript.

\section{Funding}

This research was made possible by the Network Initiative for Conservation Science (NICS), a Metropolitan Museum of Art program. Support for NICS was provided by a grant (31500630) from The Andrew W. Mellon Foundation.

\section{Availability of data and materials}

All data generated during this study are included in this published article.

\section{Competing interests}

The authors declare that they have no competing interests.

\section{Author details}

1 Department of Scientific Research, The Metropolitan Museum of Art, 1000 Fifth Avenue, New York, NY 10028, USA. ${ }^{2}$ Planning, Design and Construction, Central Park Conservancy, Inc., 14 East 60th Street, New York, NY 10022, USA.

Received: 7 May 2020 Accepted: 31 July 2020

Published online: 10 August 2020

\section{References}

1. Livingston RA. Acid rain attack on outdoor sculpture in perspective. Atmos Environ. 2016;146:332-45.

2. Kratschmer A, Odnevall Wallinder I, Leygraf C. The evolution of outdoor copper patina. Corros Sci. 2002:44:425-50.

3. Dajnowski A, Dajnowski B. Using the new GC laser cleaning system for cleaning and surface preparation for re-gilding of a large outdoor bronze monument of Alexander Hamilton. In: Targowski P, et al., editors. Proceedings of LACONA. Toruń: NCU Press; 2017. p. 217-28.

4. Matteini M, Lalli C, Tosini I, Giusti A, Siano S. Laser and chemical cleaning tests for the conservation of the Porta del Paradiso by Lorenzo Ghiberti. J Cult Herit. 2003:4:147s-51s.

5. Siano S, Salimbeni R. Advances in laser cleaning of artwork and objects of historical interest: the optimized pulse duration approach. Acc Chem Res. 2010;43(6):739-50.

6. Buccolieri G, Nassisi V, Buccolieri A, Vona F, Castellano A. Laser cleaning of a bronze bell. Appl Surf Sci. 2013;272:55-8.

7. Lee H, Cho N, Lee J. Study on surface properties of gilt-bronze artifacts, after Nd:YAG laser cleaning. Appl Surf Sci. 2013;284:235-41.

8. Sansonetti A, Colella M, Letardi P, Salvadori B, Striova J. Laser Cleaning of a nineteenth-century bronze sculpture: in situ multi-analytical evaluation. Stud Conserv. 2015;60(1):S28-33.

9. Petiti C, Toniolo L, Gulotta D, Mariani B, Goidanich S. Effects of cleaning procedures on the long-term corrosion behavior of bronze artifacts of the cultural heritage in outdoor environment. Environ Sci Pollut R. 2020. https://doi.org/10.1007/s11356-020-07814-4

10. Pini R, Siano S, Salimbeni R, Pasquinucci M, Miccio M. Tests of laser cleaning on archaeological metal artefacts. J Cult Herit. 2000;1:S129-37.

11. Colao F, Fantoni R, Lazic V, Caneve L, Giardini A, Spizzichino V. LIBS as a diagnostic tool during the laser cleaning of copper based alloys: experimental results. J Anal At Spectrom. 2004;19:502-4.

12. Garbacz H, Fortuna-Zalesna E, Marczak J, Koss A, Zatorska A, Zukowska GZ, OnyszczukT, Kurzydlowski KJ. Effect of laser treatment on the surface of copper alloys. Appl Surf Sci. 2011;257:7369-74.

13. Cacciari I, Ciofini D, Mascalchi M, Mencaglia A, Siano S. Novel approach to the microscopic inspection during laser cleaning treatments of artworks. Anal Bioanal Chem. 2012;402:1585-91.

14. Cooper M. Laser cleaning in conservation. Oxford: Butterworth Heinemann; 1998.

15. Dajnowski B, Dajnowski A. The use of new laser technology to precisely control the level of stone cleaning. In: Hughes J and Howind T, editors. Science and art: a future for stone. Proceedings of the 13th International
Congress on the Deterioration and Conservation of Stone, Vol 2. Paisley: University of the West of Scotland; 2016. p. 719-728.

16. Baranowska-Fietkiewicz A, Viegas Welosowska C, Schaefer K, Dajnowski B. Conservation of Saint George Killing the Dragon, a 16th-Century Gilt Copper Statue from Gdansk: A Collaborative Approach. In: Chemello C, Brambilla L, Joseph E, editors. Proceedings of METAL 2019. Neuchatel, Switzerland: ICOM-CC; 2019. p. 1-7.

17. Dajnowski A, Lins A. The practical use of lasers in removing deteriorated Incralac coatings from large bronze monuments. In: Radvan R, Asmus JF, Castillejo M, Pouli P, Nevin A, editors. Lasers in the conservation of artworks VIII. Boca Raton: CRC Press; 2010. p. 47-52.

18. King GA, O'Brien DJ. The influence of marine environments on metals and fabricated coated metal products, freely exposed and partially sheltered. In: KirkWW, Lawson H, editors. ASTM STP 1239 Atmospheric corrosion. Philadelphia: American Society of Materials and Testing; 1995. p. 167-92.

19. Robbiola L, Fiaud C, Pennec S. New model of outdoor bronze corrosion and its implications for conservation. In: ICOM Committee for Conservation tenth triennial meeting. Paris: International Council of Museums Committee for Conservation. 1993; 2:796-802.

20. Shedlosky TJ, Stanek KM, Bierwagen G. On-line survey results of techniques used for outdoor bronze conservation. In: AIC Objects Specialty Group Postprints. 2002; 9:3-13.

21. Reiley MC. Conservation treatment report. Central Park Conservancy: The Samuel F. B. Morse Statue; 2019.

22. Thickett $D$ and Stanley B. The use and mis-use of Renaissance wax. In: Chemello C, Brambilla $L$ and Joseph E, editors. Proceedings of METAL 2019. Neuchatel, Switzerland: ICOM-CC; 2019. p. 232-241.

23. Thickett D, Pretzel B. FTIR surface analysis for conservation. Herit Sci. 2020 https://doi.org/10.1186/s40494-020-0349-8.

24. Pitthard V, Stone R, Stanek S, Griesser M, Gersch CK, Hanzer H. Organic patinas on Renaissance and Baroque bronzes-Interpretation of compositions of the original patination by using a set of simulated varnished bronze coupons. J Cult Herit. 2011;12:44-53.

25. MacLeod ID. Bronze disease: an electrochemical explanation. ICCM Bulletin. 1981;7(1):16-26.

26. Gilberg M. History of bronze disease and its treatment. In: Daniels V, Plenderleith HJ, editors. Early advances in conservation. London: British Museum; 1988. p. 59-70.

27. Scott DA. Bronze disease: a review of some chemical problems and the role of relative humidity. J Am Inst Conservat. 1990;29(2):193-206.

28. Scott DA. Copper and bronze in art: corrosion, colorants, conservation. Los Angeles: Getty Publications; 2002.

29. Martens W, Frost RL, Kloprogge JT, Williams PA. Raman spectroscopic study of the basic copper sulphates-implications for copper corrosion and 'bronze disease'. J Raman Spectrosc. 2003;34(2):145-51.

30. Stambolov T. The corrosion and conservation of metallic antiquities and works of art. Amsterdam: CL Publication; 1985

31. NYDEC 2018. New York State ambient air quality report for 2018. New York State Department of Environmental Conservation. http://www.dec. ny.gov/docs/air_pdf/2018airqualreport.pdf. Accessed 30 Jun 2020.

32. Finnegan JE, Hummel RE, Verink ED Jr. Optical studies of dezincification in alpha-brass. Corrosion. 1981;37(5):256-61.

33. Outdoor sculpture manual-center for public buildings. Applying Benzotriazole (BTA) To Bronze. https://www.gsa.gov/technical-procedures/apply ing-benzotriazole-bta-bronze?Form_Load=88089. Accessed 30 Jun 2020

34. Mezzi A, Angelini E, De Caro T, Grassini S, Faraldi F, Riccucci C, Ingo GM. Investigation of the benzotriazole inhibition mechanism of bronze disease. Surf Interface Anal. 2012:44:968-71.

35. https://www.guidestar.org/profile/13-3022855. Accessed 30 Jun 2020.

36. Adopted Parts 205 and 200 Revised Regulatory Impact Statement Summary. https://www.dec.ny.gov/regulations/116214.html. Accessed 30 Jun 2020

37. Cicek V. Corrosion engineering and cathodic protection handbook: with extensive question and answer section. New Jersey: Wiley; 2017.

\section{Publisher's Note}

Springer Nature remains neutral with regard to jurisdictional claims in published maps and institutional affiliations. 